\title{
Simulation of Natural Convection Heat Transfer Enhancement by Nanoparticles in an Open-Enclosure Using Lattice Boltzmann Method
}

\author{
Mohammad Mehdi Keshtkar \\ Department of Mechanical Engineering, Kerman Branch, Islamic Azad University, Kerman, Iran \\ Email: mkeshtkar54@yahoo.com
}

How to cite this paper: Keshtkar, M.M. (2016) Simulation of Natural Convection Heat Transfer Enhancement by Nanoparticles in an Open-Enclosure Using Lattice Boltzmann Method. Advances in Nanoparticles, 5, 187-198.

http://dx.doi.org/10.4236/anp.2016.54020

Received: October 20, 2014

Accepted: September 4, 2016

Published: September 7, 2016

Copyright $\odot 2016$ by author and Scientific Research Publishing Inc. This work is licensed under the Creative Commons Attribution International License (CC BY 4.0).

http://creativecommons.org/licenses/by/4.0/

\begin{abstract}
A numerical analysis is performed to investigate the laminar, free convection flow in an Open Enclosure Using Lattice Boltzmann Method (LBM) in the presence of Carbon nanotube and $\mathrm{Cu}$ nanoparticles. The problem is studied for different volume fractions of nanoparticles, and aspect ratio of the cavity for various Rayligh numbers. The volume fraction of added nanoparticles to water (as base fluid) is lower than 1\% to make dilute suspensions. The study presents a numerical treatment based on LBM to model convection heat transfer of Carbon nanotube based nanofluids. Results show that adding a low value of Carbon nanotube to the base fluid led to significant enhancement of convection rate. Results show that adding nanoparticles to the base fluid enhances the rate of natural convection in a cavity. Make a comparison between Carbon nanotube and $\mathrm{Cu}$-nanoparticles shows that the Carbon nanotube-nanoparticle has better performance to enhance convection rate at comparison with $\mathrm{Cu}$ nanoparticles.
\end{abstract}

\section{Keywords}

Lattice Boltzmann Method, Carbon Nanotube, Effective Thermal Conductivity,

Effective Viscosity, Natural Convection

\section{Introduction}

The enhancement of fluids heat transfer is an interesting topic for different kinds of industrial and engineering applications. A well-known way to enhance the rate of convection heat transfer of conventional fluids such as water, oil and ethylene glycol which has low thermal conductivity [1] [2] is adding nano scale conductive particles. The added particles can be metals [3], non metals [4] or Carbon nanotubes [5] [6]. Because 
of the high thermal conductivity of these particles, they can improve conductivity of the suspensions systematically. Nowadays, nanoparticle added fluids are known as nanofluid that first time Choi [7] named this kind of fluid suspensions. He presented enhancement of convection heat transfer by adding nanoparticles to the fluids. In recent years, many studies have been conducted to study heat transfer of nanofluids numerically and experimentally [7]-[12]. Khanafer et al. [8] presented a heat transfer enhancement by adding nanoparticles to fluid in a two dimensional enclosures at natural convection regime for the different Grashof numbers. They presented an increase of $N u_{\text {ave }}$ about $7.5 \%, 12 \%, 15.5 \%$ and $20 \%$, respectively, by adding a volume fraction of added $\mathrm{Cu}$ nanoparticles to the Water equal to $4 \%, 6 \%, 8 \%$ and $10 \%$ when $\mathrm{Gr}=10^{4}$. Gherasim et al. [9] conducted to an experimental study and represented heat transfer enhancement possibility of coolants with suspended $\mathrm{Al}_{2} \mathrm{O}_{3}$ nanoparticles dispersed in water inside a radial flow cooling device. Saleh et al. [10] studied convection heat transfer of a nanofluid-filled trapezoidal enclosure. They investigated the effect of different volume fraction of $\mathrm{Al}_{2} \mathrm{O}_{3}$ and $\mathrm{Cu}$ nanoparticles on heat transfer enhancement of Water as base fluid. They reported an enhancement of natural convection heat transfer about $2.4 \%, 4.7 \%, 7.1 \%, 9.5 \%$ and $11.9 \%$ by adding a $\varphi=1 \%, 2 \%, 3 \%, 4 \%$ and $5 \%$ of $\mathrm{Al}_{2} \mathrm{O}_{3}$ nanoparticles when the angle of side walls are $23.96^{\circ}$ at $\mathrm{Gr}=10^{5}$ and also for $\mathrm{Cu}$ nanoparticles at same condition the values are about 3.9\%, 7.9\%, $11.8 \%, 15.7 \%, 19.5 \%$. In 1991, Iijima [13] discovered Carbon nanotubes as an allotrope of Carbon which is made of long-chained molecules of Carbon with Carbon atoms arranged in a hexagonal complex to form a tubular structure. In last decade Carbon nanotubes has been mentioned as attractive topic by many researches which is generally due to their special properties at physical view such mechanical and thermal properties. At this point of view, the Carbon nanotubes have extraordinary thermal properties such as thermal conductivity about twice as high as diamond [14] or thermal stability up to $2800 \mathrm{C}$ in vacuum. The higher thermal conductivity of Carbon nanotubes relative to other nanoparticles led to that the nanofluids containing cylindrical Carbon nanotubes are expected to have better heat transfer properties compared with the other nanofluids with spherical nanoparticles [15] [16]. Gavili et al. [17] simulated the mixed convection in a two-sided lid-driven differentially heated square cavity for nanofluids containing Carbon nanotubes for nanofluids. Natural convection in a square cavity and its fluid flow is a classical benchmark in heat transfer problems. Open cavities are a kind of 2-D cavity which has an open side. These kinds of cavities have special physics for both flow and temperature fields in open side because of outgoing of flow from this side. Many studies have been done on analysis of buoyant flows and their heat transfer in open cavities. Javam et al. [18] investigated stability of stratified natural convection flow in open cavities. Mohammad et al. [19] presented natural convection in an open ended cavity and slots they analyzed the effect of aspect ratio of cavity on heat transfer rate. They also presented a good procedure for simulating open boundaries in Lattice Boltzmann Method, their technique demonstrated the abilities of the LBM to simulate Natural convection in open cavities. The progress of using the Lattice Boltzmann Method (LBM) as a numerical technique to simulate the heat transfer and fluid flow has been 
obvious in the last decade [20]-[23]. The Lattice Boltzmann Method has well-known advantages such easy implementation, possibility of parallel coding and simulating of complex geometries and fluid dynamic problems such as melting, fuel cell, porous media, nanofluids and etc. The convection heat transfer of different nanoparticle-based nanofluid in a cavity was mentioned in current years [24]-[27]. Fattahi et al. [24] applied Lattice Boltzmann Method to study natural convection heat transfer of $\mathrm{Al} 2 \mathrm{O} 3$ and $\mathrm{Cu}$ nanofluid in a cavity. Their results show that increasing the solid volume fraction led to a heat transfer enhancement at any Rayleigh number and also heat transfer increases with increase in Rayleigh number for a particular volume fraction. Nemati et al. [25] applied LBM to investigate the effect of $\mathrm{Cu}, \mathrm{Al}_{2} \mathrm{O}_{3}$ and $\mathrm{CuO}$ nanoparticles on mixed convection in a lid-driven cavity. Their results show that adding nanoparticles increase the rate of mixed convection heat transfer of the base fluid for all tested Reynolds numbers. Abu-Nada and Chamkha [26] conducted to study of mixed convection heat transfer of Water- $\mathrm{Al}_{2} \mathrm{O}_{3}$ nanofluid in an inclined cavity. Heat transfer enhancement due to increase of nanoparticles volume fraction at different Richardson and Grashof numbers was presented in their results. Their results show that $N u_{a v e}$ on hot wall enhances about $3.3 \%, 8.4 \%, 11.9 \%$ and $17.2 \%$ respectively for $\varphi=2 \%, 5 \%, 7 \%$ and $10 \%$ at $R i=0.2$ and $G r=10^{2}$ when the inclination angle of the cavity is equal to zero and also this values are $3 \%, 8.5 \%, 12 \%$ and $17 \%$ for $R i=2$. The investigation of the heat transfer enhancement by adding the Carbon nanotube to the base fluid in an open-ended cavity is the main aim of the present study. Also a comparison between one type of Carbon nanotubes i.e. single wall Carbon nanotubes (SWCNT) and Cu-nanoparticles is one of the major tasks of the study. In this simulation the effective conductivity and viscosity were calculated based on the new theoretical models. The presented model by Masoumi et al. [28] is applied for effective viscosity of the $\mathrm{Cu}$ and Carbon nanotube-nanofluid. To simulate thermal conductivity of Carbon nanotube-nanofluid a new theoretical model presented by Sabbaghzadeh and Ebrahimi [29] is used. On other hand, the study applies the Patel model [30] to evaluate of the effective thermal conductivity of $\mathrm{Cu}$-nanofluid. To the best of author knowledge, the effects of carbon nanotubes on flow and thermal fields of natural convection is an unknown perspective which is not understand heretofore. Therefore, in this study the used numerical method is LBM with coupled double population approach for flow and temperature fields. The effect of the volume fraction of the $\mathrm{Cu}$ and Carbon nanotube-particles on average Nusselt number, streamlines and temperature contours is investigated for various Rayligh numbers. Also the aspect ratio of the cavity is studied as an important geometric parameter of the $2 \mathrm{D}$ cavities in different condition to exhibit the role of this parameter on both heat transfer rate and fluid flow of the base fluid and the nanofluid.

\section{Lattice Boltzmann Method for Flow and Thermal Fields}

The LBM utilizes two distribution functions, for the flow and temperature fields. It uses modeling of movement of fluid particles to define macroscopic parameters of fluid flow. The distribution functions are obtained by solving the lattice Boltzmann Equation 
(LBE), which is a special form of the Kinetic Boltzmann Equation.

The basic form of the Lattice Boltzmann Equation with an external force by introducing BGK approximations can be written as follows for the both flow and the temperature fields [20]:

$$
\begin{gathered}
f_{\alpha}\left(x+e_{\alpha} \Delta t, t+\Delta t\right)=f_{\alpha}(x, t)+\frac{\Delta t}{\tau_{m}}\left[f_{\alpha}^{e q}(x, t)-f_{\alpha}(x, t)\right]+\Delta t e_{\alpha} F_{\alpha} \\
g_{\alpha}\left(x+e_{\alpha} \Delta t, t+\Delta t\right)=g_{\alpha}(x, t)+\frac{\Delta t}{\tau_{t}}\left[g_{\alpha}^{e q}(x, t)-g_{\alpha}(x, t)\right]
\end{gathered}
$$

$\tau_{m}$ and $\tau_{t}$ are the dimensionless collision-relaxation times for the flow and temperature fields, respectively. They defined as follows [31]:

$$
\begin{gathered}
\tau_{m}=0.5+\frac{M a \cdot W \sqrt{3 P r}}{c^{2} \Delta t \sqrt{R a}} \\
\tau_{t}=0.5+\frac{3 v}{\operatorname{Prc}^{2} \Delta t}
\end{gathered}
$$

By considering D2Q9 model as shown in Figure 1, for applied lattice scheme for both flow and temperature fields, equilibrium distribution functions for flow field ( $\left.f_{\alpha}^{e q}\right)$ and temperature field $\left(g_{\alpha}^{e q}\right)$ are calculated as follows in different $\alpha$ directions:

$$
\begin{gathered}
f_{\alpha}^{e q}=w_{\alpha} \rho\left[1+3\left(e_{\alpha} \cdot \boldsymbol{u}\right)+\frac{9}{2}\left(e_{\alpha} \cdot \boldsymbol{u}\right)^{2}-\frac{3}{2} \boldsymbol{u}^{2}\right] \\
g_{0}^{e q}=-w_{0} \rho R T\left[\frac{3}{2} \boldsymbol{u}^{2}\right] \\
g_{\alpha}^{e q}=w_{\alpha} \rho R T\left[\frac{3}{2}+\frac{3}{2}\left(e_{\alpha} \cdot \boldsymbol{u}\right)+\frac{9}{4}\left(e_{\alpha} \cdot \boldsymbol{u}\right)^{2}-\frac{3}{2} \boldsymbol{u}^{2}\right] \text { for } \alpha=1,2,3,4 \\
g_{\alpha}^{e q}=w_{\alpha} \rho R T\left[3+6\left(e_{\alpha} \cdot \boldsymbol{u}\right)+\frac{9}{2}\left(e_{\alpha} \cdot \boldsymbol{u}\right)^{2}-\frac{3}{2} \boldsymbol{u}^{2}\right] \text { for } \alpha=5,6,7,8
\end{gathered}
$$

For these model the values of $e_{\alpha}$ and $w_{\alpha}$ for various $\alpha$ directions will be, respectively:

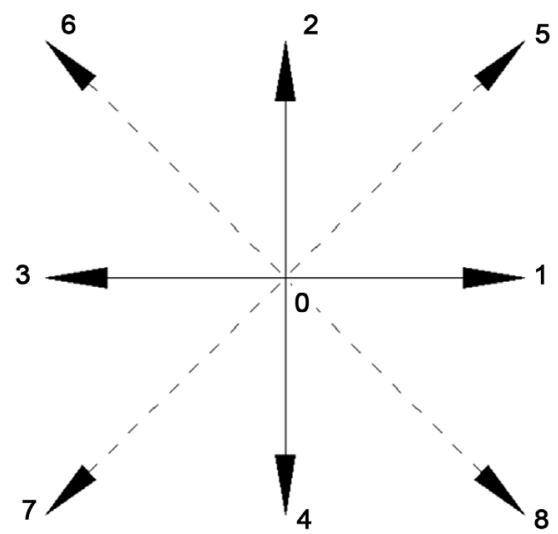

Figure 1. Discrete velocity vectors for the D2Q9 model of LBM. 


$$
\begin{aligned}
& e_{\alpha}=\left\{\begin{array}{lll}
(0,0) & & \alpha=0 \\
c\left(\cos \theta_{\alpha}+\sin \theta_{\alpha}\right), & \theta_{\alpha}=(\alpha-1) \pi / 2 & \alpha=1,2,3,4 \\
\sqrt{2} c\left(\cos \theta_{\alpha}+\sin \theta_{\alpha}\right), & \theta_{\alpha}=(\alpha-5) \pi / 2+\pi / 4 & \alpha=5,6,7,8
\end{array}\right. \\
& w_{\alpha}= \begin{cases}4 / 9 & \alpha=0 \\
1 / 9 & \alpha=1,2,3,4 \\
1 / 36 & \alpha=5,6,7,8\end{cases}
\end{aligned}
$$

In order to incorporate external force in collision part of Lattice Boltzmann model (Equation (1)), radiation heat transfer and viscous dissipation are neglected at the numerical simulation. Therefore, to capture buoyancy force effects in the flow field, the Boussinesq approximation is applied. Thus, to model buoyancy force in Equation (1), the external force needs to be assumed as below in the needed direction:

$$
F_{\alpha}=3 w_{\alpha} g_{\alpha} \beta\left(T-T_{r e f}\right)
$$

Finally, macroscopic variables can be calculated as follows:

Flow density: $\rho=\sum_{\alpha} f_{\alpha}$, Momentum: $\rho u_{i}=\sum_{\alpha} f_{\alpha} c_{i \alpha}$, Temperature:

$$
T=\sum_{\alpha} g_{\alpha}
$$

\section{Nanofluids Modeling}

At present study, nanofluid is assumed as a single phase fluid. Thermal diffusivity of nanofluid is as follows:

$$
\alpha_{n f}=\frac{k_{n f}}{\left(\rho c_{p}\right)_{n f}}
$$

The density, heat capacitance and thermal expansion of nanofluid can be defined as [32]:

$$
\rho_{n f}=(1-\varphi) \rho_{f}+\varphi \rho_{s}, \quad\left(\rho c_{p}\right)_{n f}=(1-\varphi)\left(\rho c_{p}\right)_{f}+\varphi\left(\rho c_{p}\right)_{s}, \quad \beta_{n f}=(1-\varphi) \beta_{f}+\varphi \beta_{s}
$$

The effects of nanoparticles on the viscosity of nanofluids are introduced by the socalled apparent viscosity which is presented by $\mu_{\text {app }}$ [28]:

$$
\mu_{n f}=\mu_{b f}+\mu_{a p p}=\mu_{b f}+\frac{\rho_{n p} V_{\text {Brownian }} d_{n p}}{72 C \delta}
$$

\section{Main Problem}

In the present study, the effects of Carbon nanotube and $\mathrm{Cu}$-nanoparticles on natural convection heat transfer in a $2 \mathrm{D}$ deep open cavity are investigated using the Lattice Boltzmann Method based on double population approach and bounce back method. The horizontal walls of the cavity are assumed to be insulated while the left wall is maintained at a uniform temperature $\left(T_{h}\right)$ differentially higher than the open end side temperature $\left(T_{c}\right)$. The considered physical system is presented in Figure 2. The effect of Carbon nanotube/Cu-nanoparticles on both fluid flow and heat transfer is investi- 


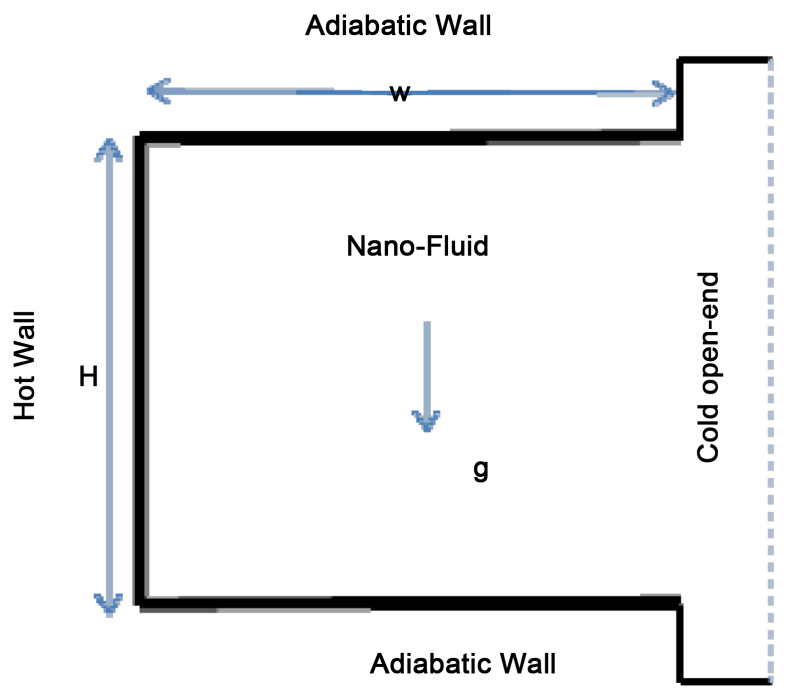

Figure 2. Schematic geometry of the problem.

gated for different Rayligh numbers at the range of $10^{3} \leq R a \leq 10^{5}$ while the Prandtl number of based fluid (Water) at reference temperature $\left(22^{\circ} \mathrm{C}\right)$ is 6.57 . It is assumed that the both nanotubes and nanoparticles are in constant form with uniform diameter which are at thermal equilibrium state with base fluid and also the nanotubes and nanoparticles have same velocity with the base fluid thus there is no sleep velocity between added nanotubes/nanoparticles and molecules of the base fluid. Thermo-physical properties of Carbon nanotube-particles, $\mathrm{Cu}$-nanoparticles and Water at reference temperature are tabulated in Table 1.

The dimensionless quantities are as follows:

$$
x=\frac{\bar{x}}{H}, y=\frac{\bar{y}}{H}, u=\frac{\bar{u}}{u_{0}}, v=\frac{\bar{v}}{u_{0}}, \theta=\frac{T-T_{c}}{T_{h}-T_{c}}, \operatorname{Pr}=\frac{v \rho C_{p}}{K}, R a=\frac{g \beta \Delta \theta W^{3}}{\alpha v}
$$

The boundary conditions on the solid walls are in the following forms:

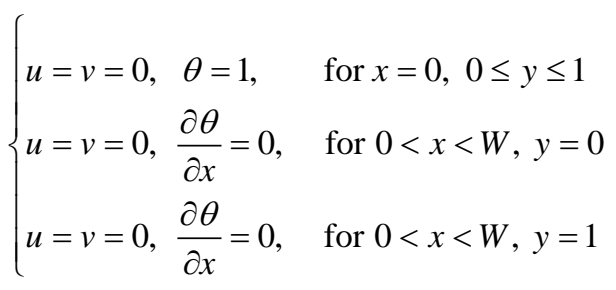

The boundary conditions on the east open side $(x=W, 0 \leq y \leq 1)$ are in the following forms:

$$
\begin{cases}\frac{\partial u}{\partial x}=0, \frac{\partial v}{\partial x}=0, \frac{\partial \theta}{\partial x}=0 & \text { if } u>0 \\ \frac{\partial u}{\partial x}=0, \frac{\partial v}{\partial x}=0, \theta=0 & \text { if } u<0\end{cases}
$$

The boundary conditions in the LBM can be implemented through the distribution function. For both flow and thermal fields, the distribution functions out of the domain 
Table 1. Thermo-physical properties of the base fluid and nanoparticles [17] [30].

\begin{tabular}{cccc}
\hline Property & Water & $\mathrm{Cu}$ & Carbon nanotube \\
\hline$c_{p}(\mathrm{~J} / \mathrm{kg} \cdot \mathrm{K})$ & 4179 & 383 & 709 \\
$\rho\left(\mathrm{kg} / \mathrm{m}^{3}\right)$ & 997.1 & 8954 & 2200 \\
$k(\mathrm{~W} / \mathrm{m} \cdot \mathrm{K})$ & 0.613 & 400 & 2000 \\
$\beta \times 10^{5}\left(\mathrm{~K}^{-1}\right)$ & 21 & 0.167 & 1.5 \\
$d_{p}(\mathrm{~nm})$ & 0.384 & 100 & 10 \\
\hline
\end{tabular}

are known from the streaming process. The unknown distribution functions are those toward the domain.

\section{Result and Discussion}

The presence of nanotube particles with high thermal conductivity in suspensions has different effects on temperature and flow fields. The effect of added nanotubes and $\mathrm{Cu}$ nanoparticles on flow and temperature fields of the Water (the base fluid) is presented in Figure 3 for the open cavity with $A=1$ at different Rayligh numbers. At the present study to be sure that nanofluid behavior is completely same as single phase fluid, the volume fraction value of added nanotubes is less than $1 \%$ to make a dilute suspension, therefore it can be acceptable that the overall shape of the contours are same for both pure fluid and nanofluid with added nanotube particles. Also, the maximum value of stream-function in the flow field is presented in this figure for Water, Water$\mathrm{Cu}$ and Water-Carbon nanotube nanofluid at different case studies.

The presented values for maximum stream-function shows that adding the $1 \%$ volume fraction of Carbon nanotube-nanoparticles increase the maximum value of streamfunction about $57 \%, 59 \%$ and $75 \%$ respectively for $R a=10^{3}$ and $10^{5}$ when the $\mathrm{Cu}$ nanoparticles change the value of maximum stream function about $10 \%, 11 \%$ and $14 \%$ respectively for $R a=10^{3}$ and $10^{5}$. The increase of stream-function values shows that the nanoparticles have more effect on fluid flow at high Rayligh numbers which it is due the importance of the fluid density at high Rayligh numbers when natural convection is completely dominant.

Although, the $\mathrm{Cu}$ nanoparticles have higher density, the results show that Carbon nanotube-nanoparticles have more positive effects on flow field of the base fluid. The Figure 4 presents the variation of velocity components of Carbon nanotube-nanofluid at horizontal mid-section of the cavity are shown for different Rayligh numbers and volume fraction of the added nanotubes when the aspect ratio is equal to unity. It is visible that adding nanoparticles to the base fluid has more obvious effects at high Rayligh numbers. At studying of convection problems in 2D cavities, aspect ratio of the cavity must be mentioned as characteristic parameter of the cavity. Therefore, the streamlines and temperature contours of the base fluid and Carbon nanotube-nanofluid $(\varphi=1 \%)$ in the cavity with different values of aspect ratio are presented in Figure 5 when $R a=10^{5}$. 

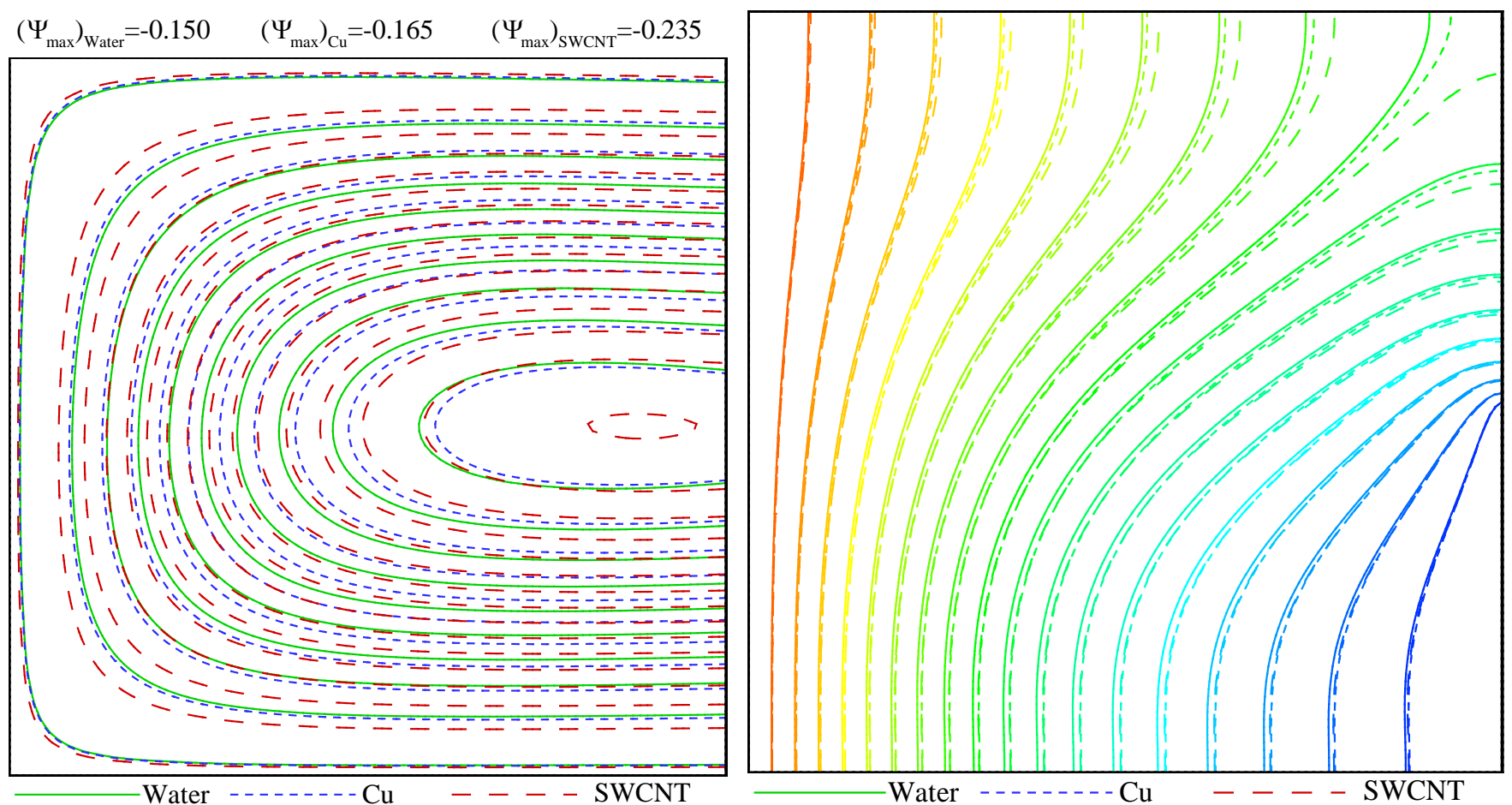

(a)

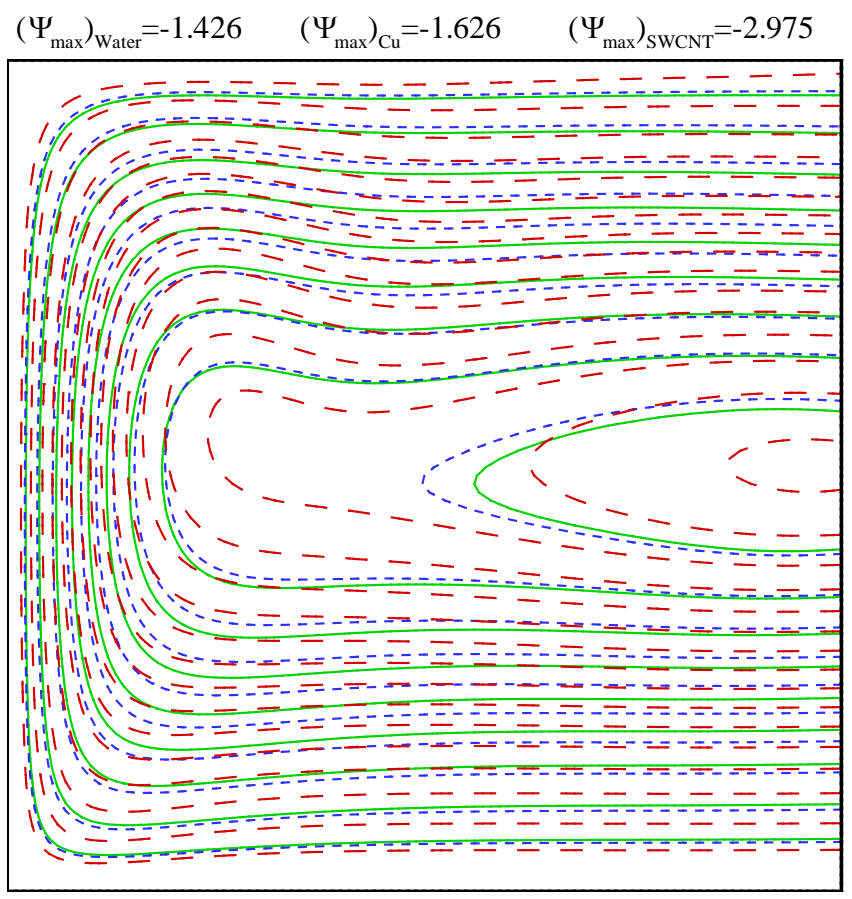

Water

---- SWCNT

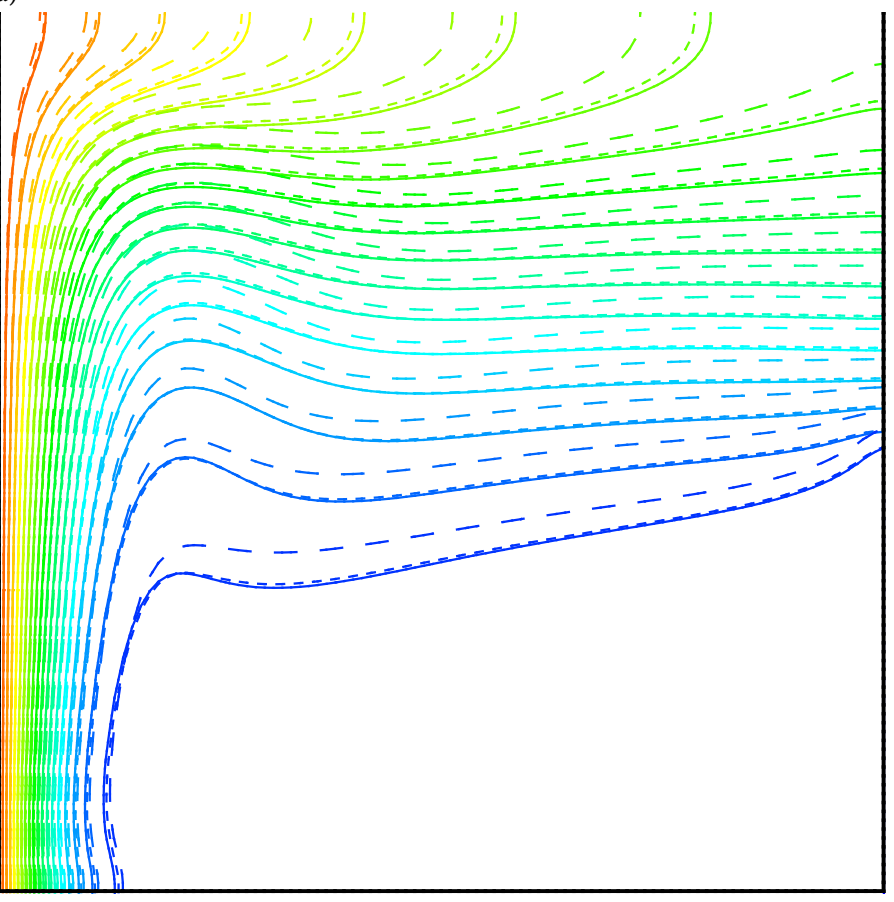

Water -.-.-.-Cu $\quad-\quad--$ SWCNT

$\mathrm{T}: \quad 0.0$

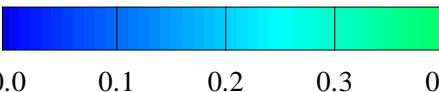

0.4

(b)

Figure 3. Streamlines and temperature contours of the base fluid, SWCNT and Cu-nanofluid $(\varphi=1 \%)$ at $A=1$. (a) $R a=10^{3} ;(b)$ $R a=10^{5}$. 


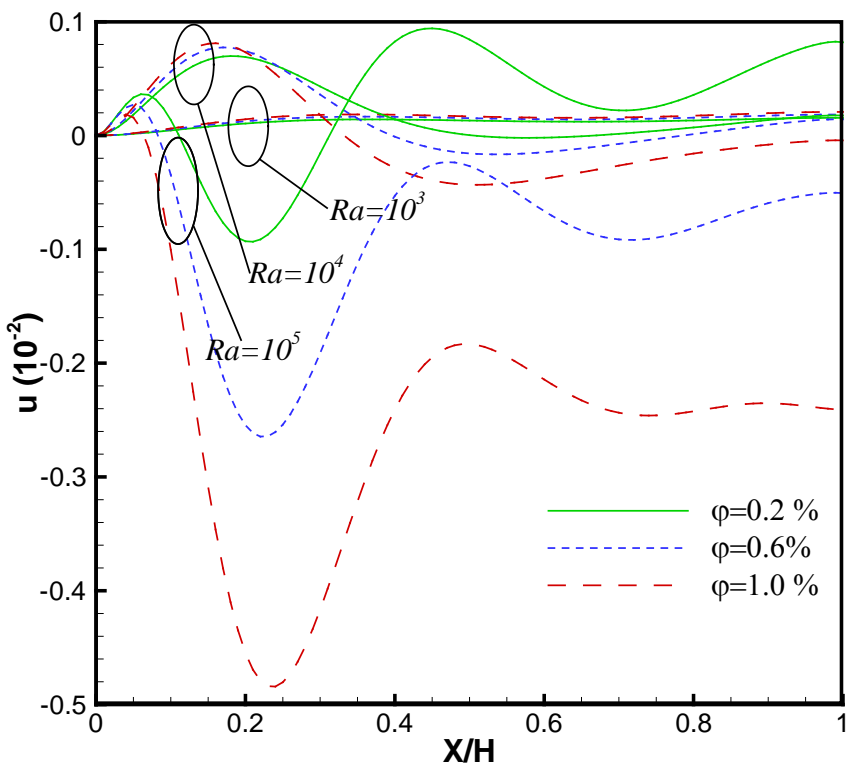

(a)

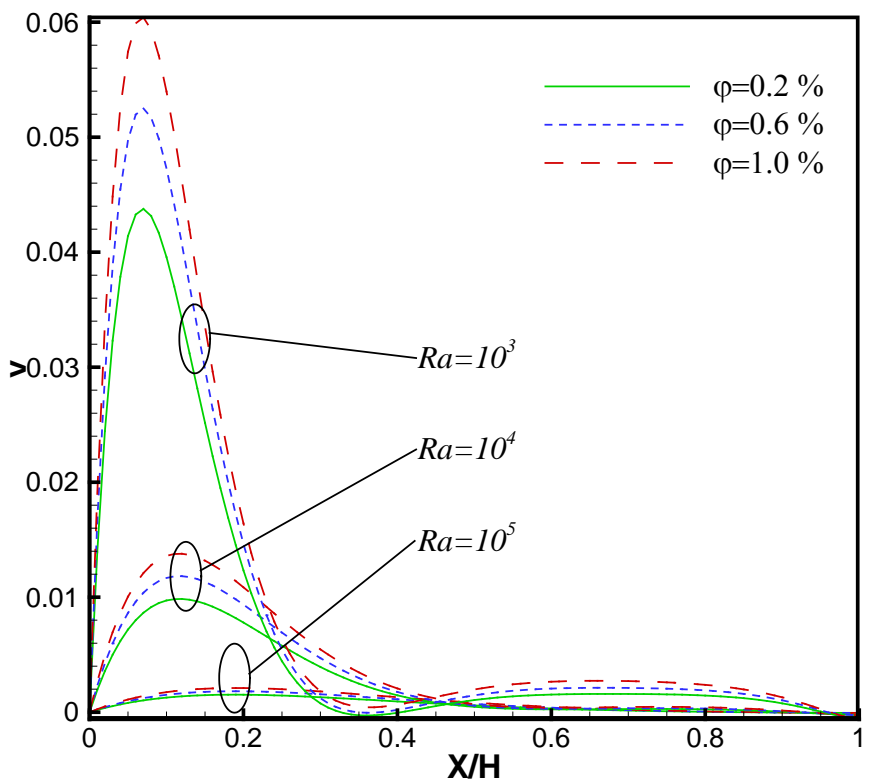

(b)

Figure 4. Effect of different volume fractions of nanotubes on $u$-velocity (a) and $v$-velocity (b) in horizontal mid-section of the cavity at different $R a$ when $A=1$.
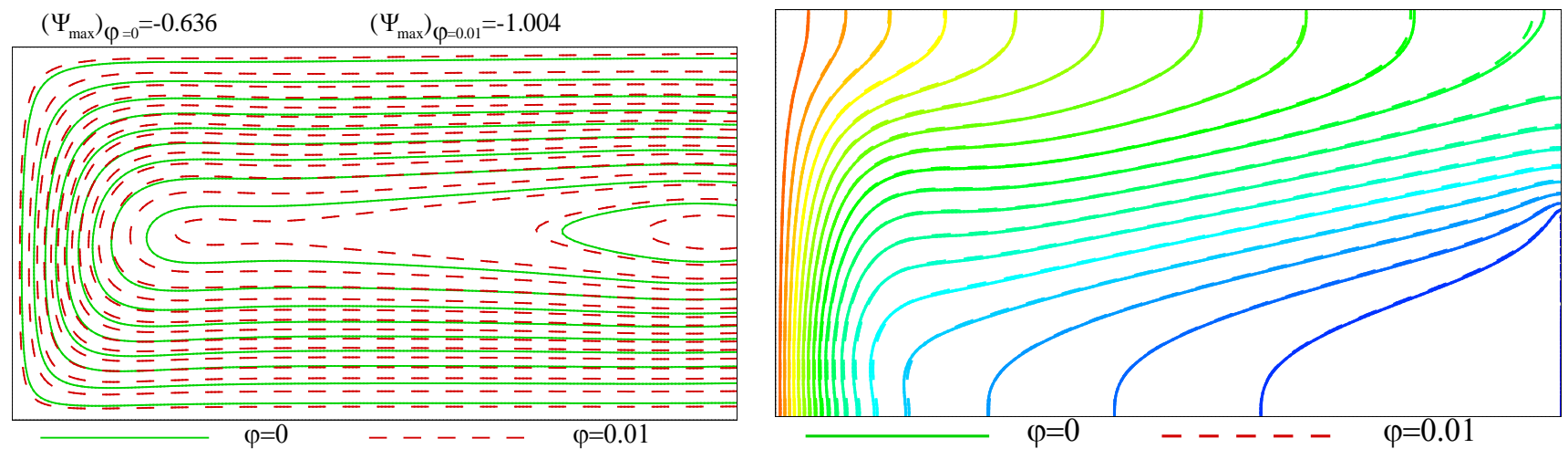

(a)
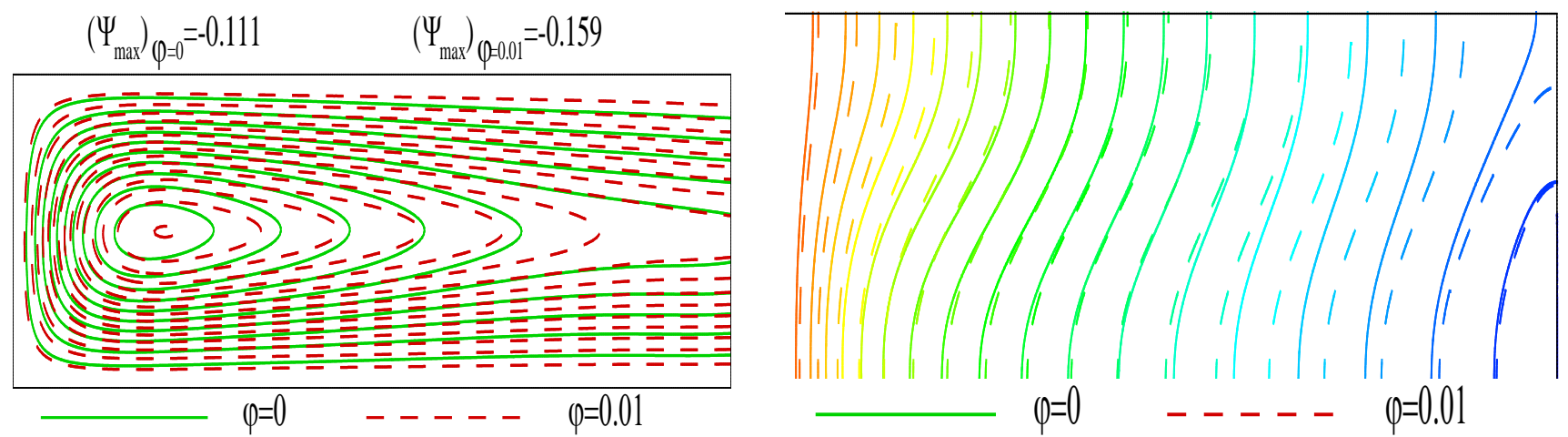

(b)

Figure 5. Streamlines and temperature contours of the base fluid, Carbon nanotube and Cu-nanofluid $(\varphi=1 \%)$ at $R a=10^{5}$. (a) $A=2$; (b) $A=4$. 
The overall view of this figure shows that the increase of cavity's aspect ratio leads to reduce of flow strength. The distance between hot and cold side in an enclosure is one of most important parameter of natural convection regime, the increase of this distance change the natural convection regime to a conduction manner in the problem domain.

\section{Conclusions}

The effect of Carbon nanotube and $\mathrm{Cu}$ nanoparticles on natural convection heat transfer in an open-end enclosure was studied numerically. The problem was investigated at different aspect ratios of the cavity $(1 \leq A \leq 4)$ and the volume fractions of Carbon nanotube and $\mathrm{Cu}$-nanoparticles $(0 \leq \varphi \leq 1 \%)$ when Rayligh number vary from $10^{3}$ to $10^{5}$. Some of most important results that have been achieved in this study are as follows:

- Results show that adding a low value of Carbon nanotube to the base fluid led to significant enhancement of convection heat transfer.

- The heat transfer rate is at closed relation with thermal conductivity of the suspensions therefore the use of nanoparticles with better thermal conductivity leads to better heat transfer enhancement at base fluid.

- Make a comparison between Carbon nanotube and $\mathrm{Cu}$-nanoparticles shows that the Carbon nanotube-nanoparticle has better performance to enhance convection rate.

- The aspect ratio of the cavity plays an important role on natural convection heat transfer. An increase of this parameter leads to heat transfer reduction in a $2 \mathrm{D}$ deep open cavity.

- Rayligh number loses its importance on natural convection in the high aspect ratios.

\section{References}

[1] Marquis, F.D.S. and Chibante, L.P.F. (2005) Improving the Heat Transfer of Nanofluids and Nano Lubricants with Carbon Nanotubes. The Journal of the Minerals, Metals \& Materials Society, 57, 57-32.

[2] Tiwari, R.K. and Das, M.K. (2007) Heat Transfer Augmentation in a Two-Sided Lid-Driven Differentially Heated Square Cavity Utilizing Nanofluids. International Journal Heat Mass Transfer, 50, 2002-2018. http://dx.doi.org/10.1016/j.ijheatmasstransfer.2006.09.034

[3] Eastman, J.A., Choi, S.U.S., Li, S. and Thompson, L.J. (2001) Anomalously Increased Effective Thermal Conductivities of Ethylene Glycol-Based Nanofluids Containing Copper Nanoparticles. Applied Physics Letter, 78, 718-724. http://dx.doi.org/10.1063/1.1341218

[4] Jamshidi, N., Farhadi, M., Ganji, D.D. and Sedighi, K. (2012) Experimental Investigation on the Viscosity of Nanofluids. International Journal of Engineering - Transaction (B), 25, 201-209.

[5] Choi, S.U.S., Zhang, Z.G., Lockwood, F.E. and Grulke, E.A. (2001) Anomalous Thermal Conductivity Enhancement in Nanotube Suspensions. Applied Physics Letter, 79, 2252 2256. http://dx.doi.org/10.1063/1.1408272

[6] Xie, H., Youn, H.W. and Choi, M. (2003) Nanofluids Containing Multiwalled Carbon Nanotubes and Their Enhanced Thermal Conductivities, Journal Applied Physics, 94, 49674973. http://dx.doi.org/10.1063/1.1613374

[7] Choi, U.S. (1995) Enhancing Thermal Conductivity of Fluids with Nanoparticles, Developments and Application of Non-Newtonian Flows. ASME Journal of Heat Transfer, 66, 
99-105.

[8] Khanafer, K., Vafai, K. and Lightstone, M. (2003) Buoyancy-Driven Heat Transfer Enhancement in a Two-Dimensional Enclosure Utilizing Nanofluids. International Journal Heat Mass Transfer, 46, 3639-3653. http://dx.doi.org/10.1016/S0017-9310(03)00156-X

[9] Gherasim, I., Roy, G., Nguyen, C.T. and Vo-Ngoc, D. (2009) Experimental Investigation of Nanofluids in Confined Laminar Radial Flows. International Journal Thermal Science, 48, 1486-1493. http://dx.doi.org/10.1016/j.ijthermalsci.2009.01.008

[10] Saleh, H., Roslan, R. and Hashim, I. (2011) Natural Convection Heat Transfer in a Nanofluid-Filled Trapezoidal Enclosure. International Journal Heat Mass Transfer, 54, 194-201. http://dx.doi.org/10.1016/j.ijheatmasstransfer.2010.09.053

[11] Mirmasoumi, S. and Behzadmehr, A. (2008) Numerical Study of Laminar Mixed Convection of a Nanofluid in A Horizontal Tube Using Two-Phase Mixture Model. Applied Thermal Engineering, 28, 717-727. http://dx.doi.org/10.1016/j.applthermaleng.2007.06.019

[12] Izadi, M., Behzadmehr, A. and Jalali-Vahida, D. (2009) Numerical Study of Developing Laminar Forced Convection of a Nanofluid in an Annulus. International Journal Thermal Science, 48, 2119-2129. http://dx.doi.org/10.1016/j.ijthermalsci.2009.04.003

[13] Iijima, S. and Ichihashi, T. (1993) Single-Shell Carbon Nanotubes of 1-nm Diameter. Nature, 363, 603-605. http://dx.doi.org/10.1038/363603a0

[14] Thostenson, E.T., Ren, Z. and Chou, T.W. (2001) Advances in the Science and Technology of Carbon Nanotubes and Their Composites: A Review. Composite Science Technology, 61, 1899-1912. http://dx.doi.org/10.1016/S0266-3538(01)00094-X

[15] Berber, S., Kwon, Y.K. and Tomanek, D. (2000) Unusually High Thermal Conductivity of Carbon Nanotubes. Physics Review Letter, 84, 4613-4616. http://dx.doi.org/10.1103/PhysRevLett.84.4613

[16] Kim, P., Shi, L., Majumdar, A. and Mceuen, P.L. (2001) Thermal Transport Measurements of Individual Multi Walled Nanotubes. Physical Review Letters, 87, Article ID: 215502. http://dx.doi.org/10.1103/PhysRevLett.87.215502

[17] Gavili, A., Dallali Isfahani, T. and Sabbaghzadeh, J. (2011) The Variation of Heat Transfer in a Two-Sided Lid-Driven Differentially Heated Square Cavity with Nanofluids Containing Carbon Nanotubes for Physical Properties of Fluid Dependent on Temperature. International Journal for Numerical Methods in Fluids, 68, 302-323. http://dx.doi.org/10.1002/fld.2507

[18] Javam, A. and Armfield, S.W. (2001) Stability and Transition of Stratified Natural Convection Flow in Open Cavities. Journal of Fluid Mechanics, 44, 285-303.

[19] Mohamad, A.A., El-Ganaoui, M. and Bennacer, R. (2009) Lattice Boltzmann Simulation of Natural Convection in an Open Ended Cavity. International Journal of Thermal Sciences, 48, 1870-1875. http://dx.doi.org/10.1016/j.ijthermalsci.2009.02.004

[20] Mohamad, A. (2007) Applied Lattice Boltzmann Method for Transport Phenomena, Momentum, Heat and Mass Transfer. Sure, Calgary.

[21] Jafari, M., Farhadi, M. and Sedighi, K. (2012) Effect of Wavy Wall on Convection Heat Transfer of Water- $\mathrm{Al}_{2} \mathrm{O}_{3}$ Nanofluid in a Lid-Driven Cavity Using Lattice Boltzmann Method. International Journal of Engineering, Transactions A: Basics, 25, 165-175. http://dx.doi.org/10.5829/idosi.ije.2012.25.02a.06

[22] Mousavi, S.E., Sedighi, K., Farhadi, M. and Fattahi, E. (2013) Lattice Boltzmann Simulation of Deformation and Breakup of a Droplet under Gravity Force Using Inter particle Potential Model. International Journal of Engineering, Transactions A: Basics, 26, 781-794. 
[23] Javaran, E.J., Nassab, S.A.G. and Jafari, S. (2010) Thermal Analysis of a 2-D Heat Recovery System Using Porous Media Including Lattice Boltzmann Simulation of Fluid Flow. International Journal of Thermal Sciences, 49, 1031-1041.

http://dx.doi.org/10.1016/j.ijthermalsci.2009.12.004

[24] Fattahi, E., Farhadi, M., Sedighi, K. and Nemati, H. (2012) Lattice Boltzmann Simulation of Natural Convection Heat Transfer in Nanofluids. International Journal of Thermal Sciences, 52, 137-144. http://dx.doi.org/10.1016/j.ijthermalsci.2011.09.001

[25] Nemati, H., Farhadi, M., Sedighi, K. and Fattahi, E. (2010) Lattice Boltzmann Simulation of Nanofluid in Lid-Driven Cavity. International Communication in Heat and Mass Transfer, 37, 1528-1534. http://dx.doi.org/10.1016/j.icheatmasstransfer.2010.08.004

[26] Abu-Nadaa, E. and Chamkhac, A.J. (2010) Mixed Convection Flow in a Lid-Driven Inclined Square Enclosure Filled with a Nanofluid. European Journal of Mechanics B/ Fluids, 29, 472-482. http://dx.doi.org/10.1016/j.euromechflu.2010.06.008

[27] Talebi, F., Mahmoudi, A.H. and Shahi, M. (2010) Numerical Study of Mixed Convection Flows in a Square Lid-Driven Cavity Utilizing Nanofluid. International Communication in Heat and Mass Transfer, 37, 79-90.

http://dx.doi.org/10.1016/j.icheatmasstransfer.2009.08.013

[28] Masoumi, N., Sohrabi, N. and Behzadmehr, A. (2009) A New Model for Calculating the Effective Viscosity of Nanofluids. Journal of Physics D: Applied Physics, 42, Article ID: 055501. http://dx.doi.org/10.1088/0022-3727/42/5/055501

[29] Sabbaghzadeh, J. and Ebrahimi, S. (2007) Effective of Thermal Conductivity of Nanofluids Containing Cylindrical Nanoparticles. International Journal of NanoScience, 6, 45-49. http://dx.doi.org/10.1142/S0219581X07004286

[30] Patel, H.E., Pradeep, T., Sundararajan, T. and Das, S.K. (2005) A Micro Convection Model for Thermal Conductivity of Nanofluid. Pramana Journal of Physics, 65, 863-869. http://dx.doi.org/10.1007/BF02704086

[31] He, Y., Qi, C., Hu, Y., Qin, B. and Ding, Y. (2011) Lattice Boltzmann Simulation of Alumina-Water Nanofluid in a Square Cavity. Nanoscale Research Letters, 6, 184-193. http://dx.doi.org/10.1186/1556-276X-6-184

[32] Xuan, Y. and Roetzel, W. (2000) Conceptions for Heat Transfer Correlation of Nanofluids. International Journal of Heat and Mass Transfer, 43, 3701-3707. http://dx.doi.org/10.1016/S0017-9310(99)00369-5 
Submit or recommend next manuscript to SCIRP and we will provide best service for you:

Accepting pre-submission inquiries through Email, Facebook, LinkedIn, Twitter, etc. A wide selection of journals (inclusive of 9 subjects, more than 200 journals)

Providing 24-hour high-quality service

User-friendly online submission system

Fair and swift peer-review system

Efficient typesetting and proofreading procedure

Display of the result of downloads and visits, as well as the number of cited articles

Maximum dissemination of your research work

Submit your manuscript at: http://papersubmission.scirp.org/

Or contact anp@scirp.org 